\title{
French Validation of the Domestic Violence Myth Acceptance Scale (DVMAS)
}

Affilia: Journal of Women and Social

\author{
Solveig Lelaurain', David Fonte', Pierluigi Graziani ${ }^{1,2}$ \\ and Grégory Lo Monaco'
}

\begin{abstract}
The Domestic Violence Myth Acceptance Scale (DVMAS) was developed to study widely held stereotypical attitudes and beliefs, which contribute to the minimization and justification of intimate partner violence (IPV). This research aims to validate a French version of the DVMAS. In Study I $(N=282)$, we tested the structure of the DVMAS. Results revealed that the scale displayed reasonable fit indices. In Study $2(N=296)$, we assessed convergent and discriminant validity. The scale was positively correlated with belief in a just world, ambivalent sexism, and gender-specific system justification. In Study $3(N=156)$, we tested the predictive validity of the DMAS. Results showed that participants who endorsed more myths also placed more responsibility on the victim of IPV, exonerated the aggressor more, and perceived the violence as less severe. Broadly speaking, results provide evidence of reliability of the French DVMAS and domestic violence myths are commonplace and impact the representation of violence. This scale could contribute to improve certain aspects at stake in the negative judgments against victims of IPV in France.
\end{abstract}

\section{Keywords}

aggressor exoneration, domestic violence myths, French validation, intimate partner violence, victim blame

\footnotetext{
"He was drunk, and he lost control"

"Intimate partner violence affects women who have a psychological weakness"

"She can just leave if she's not happy!"
}

Intimate partner violence (IPV) perpetrated by a man against a woman is a global public concern affecting between $10 \%$ and $71 \%$ of women during their lifetime according to the country in which

\footnotetext{
' Aix Marseille Univ, LPS, Aix en Provence, France

${ }^{2}$ UNIMES, Université de Nîmes, Nîmes, France

Corresponding Author:

Solveig Lelaurain, Aix Marseille Univ, LPS, Aix en Provence, France, 29 Avenue Robert Schuman, I362I Aix-en-Provence, France.

Email: solveig.lelaurain@gmail.com
} 
they live (Garcia-Moreno, Jansen, Ellsberg, Heise, \& Watts, 2006). Despite awareness of the scope of this phenomenon and the implementation of a range of recommendations to deal with it in recent years (e.g., prevention, laws, specialized associations), a number of help-seeking barriers remain (for a review, see Lelaurain, Graziani, \& Lo Monaco, 2017). Indeed, IPV is rarely denounced and prosecuted. Many survivors report not having spoken about the violence to anyone, even relatives (Jaspard et al., 2003) or do not disclose the violence or seek help to deal with it until many years after the abuse began (Meyer et al., 2007). More specifically in France, two thirds of IPV victims are still living with their abuser (Bauer \& Soullez, 2012). Moreover, only $28 \%$ have already been to the police, and only $16 \%$ have already filed a complaint (Morin, Jaluzot, \& Picard, 2013). One of the most important scientific issues in this field therefore concerns the understanding of the psychological and social mechanisms underlying the persistence of this violence and the help-seeking barriers faced by victims.

Many of these barriers are linked to socially shaped beliefs, norms, and values (Liang, Goodman, Tummala-Narra, \& Weintraub, 2005). Several researchers have undertaken to assess the prevalence of negative attitudes toward the survivors of IPV and the tolerance of this kind of behavior. For instance, there is a belief that women's treatment of men accounted for some violence or that women could escape from violent relationships "if they really wanted to" (Worden \& Carlson, 2005; see also Policastro \& Payne, 2013). These socially shared beliefs contribute to the nonrecognition or acceptance of IPV and affect judgments toward survivors (Baldry \& Pagliaro, 2014; Taylor \& Sorenson, 2005). They also help to reduce social support for them and play a major role in the response to this violence and in the way that victims deal with it (Flood \& Pease, 2009). Attitudes and beliefs about IPV have been a long-standing concern in the literature and regarded as important for understanding the factors that cause and perpetuate the abuse of women (see Saunders, Lynch, Grayson, \& Linz, 1987). Examining these psychosocial factors is of major importance if we are to better understand the IPV phenomenon in France, and specifically, if we are to identify beliefs that may help to promote its acceptance in this specific context.

\section{Legitimizing Myths of Domestic Violence}

Peters $(2003,2008)$ suggested calling these negative attitudes "domestic violence myths." He defined them as "stereotypical beliefs about domestic violence that are generally false but are widely and persistently held, and which serve to minimize, deny, or justify physical aggression against intimate partners" (2008, p. 5). These myths legitimize IPV in three ways, as they minimize its seriousness and occurrence (e.g., "Domestic violence does not affect many people"), hold the victim responsible for the abuse (e.g., "Women are used to provoking their partners"), and exonerate the perpetrator (e.g., "He was probably abused as a child"). Consequently, they reduce social support for survivors, who are no longer perceived as innocent victims because they are thought to have consciously or unconsciously decided to be beaten and could have avoided violence.

Domestic violence myths are based on two different conceptual frameworks: feminist theories about IPV (Bograd, 1990; Dobash, Dobash, Wilson, \& Daly, 1992; Hunnicutt, 2009) and the defensive attribution theory (Burger, 1981; Thornton, 1984). The feminist perspective situates IPV within the historical, cultural, and ideological structures associated with patriarchy. In other words, it roots IPV within the structural framework, which organizes social relations hierarchically between men and women. Thus, IPV is seen as a manifestation of gender inequality and as a mechanism for the control and the subordination of women by men. According to the feminist perspective, patriarchal violence against women is sustained by myths that legitimize violence (Burt, 1980; Giger, Gonçalves, \& Almeida, 2016), most well-known of which are rape myths (Burt, 1980). These myths are defined as "descriptive or prescriptive beliefs about rape (i.e., about its causes, contexts, consequences, perpetrators, victims, and their interaction) that serve to deny, downplay, or justify sexual 
violence that men commit against women" (Bohner, 1998, p. 14). According to the theory of defensive attributions, when situations have personal relevance for individuals, they use attributions of responsibility as part of a psychological defense against cognitive and affective threat (Burger, 1981). Specifically, people are motivated to blame crime victims in order to defend themselves against the idea of enduring (harm avoidance) or causing harm (blame avoidance). Defensive attributions can be seen as a manifestation of the need to perceive events as ordered and controllable in a "just world" (Lerner, 1980) where people get what they deserve. According to Peters (2008), the persistence of these myths confirms their psychological and sociological function. At the social level, they serve to support patriarchy and they contribute to the acceptance and legitimization of IPV. At the psychological level, they play a defensive role for the individuals since they reduce the threat of danger for women as they protect themselves from the threat of being a potential victim by isolating IPV to a very restricted group of people; they also reduce the feeling of guilt for men as they protect the group identity and the paternalistic system by avoiding them seeing themselves as a potential aggressor (Giger et al., 2016).

\section{The Domestic Violence Myth Acceptance Scale (DVMAS): A Pertinent Measurement Tool}

In order to assess adherence to these legitimizing myths of IPV, Peters (2008) developed a psychometric tool on the basis of (1) a literature review in this field of research (in particular concerning rape myths; see Burt, 1980), (2) the clinical experience of experts, (3) existing scales about rape and IPV, and (4) a review of popular culture. In its final version, the DVMAS is an 18-item multidimensional scale composed of four dimensions. The first factor is called "Character blame of the victims" (e.g., "Some women unconsciously want their partners to control them"; 7 items). The second concerns "Behavior blame of the victims" (e.g., "Women who flirt are asking for it"; 5 items). The third factor is called "Minimization of the seriousness and extent of the abuse" (e.g., "Domestic violence rarely happens in my neighborhood"; 3 items) and the fourth "Exoneration of the perpetrator" (e.g., "When a man is violent, it is because he lost control of his temper"; 3 items). Responses are given on a 7-point Likert-type scale ranging from 1 (strongly disagree) to 7 (strongly agree) and averaged, with higher scores representing greater endorsement of myths surrounding IPV acceptance.

Concerning the importance of the DVMAS in the literature, Jankowski, Johnson, Holtz Damron, and Smischney (2011) reported that research on domestic violence myths has been more limited relative to rape myth acceptance studies. The authors argued that one reason for it might be the historical tensions and discrepancies on how to conceptualize IPV between feminist perspective and family violence perspective. Otherwise, studies using the DVMAS have mainly been carried out in the United States, and to our knowledge, only one validation in another language has been carried out (i.e., adapted for Portuguese, see Giger et al., 2016). This echoed literature reviews concerning IPV showing that most of the studies in this field of research are American and highlighting the need to develop studies in other contexts (Lelaurain et al., 2017; Montalvo-Liendo, 2009).

Convergent and discriminant validity of DVMAS has also been supported. This scale has been shown to be correlated positively with a set of belief systems identified as being at work in the maintenance of the social hierarchy between genders, such as the adherence to traditional beliefs about women's roles (Jankowski et al., 2011; Peters, 2008), the adherence to sex role stereotypes (Giger et al., 2016; Peters, 2008), hypermasculinity attitudes (Klaw, Demers, \& Da Silva, 2016), and acceptance of rape myths (Jankowski et al., 2011; Peters, 2008). The DVMAS has also been associated with religiosity (Jankowski et al., 2011), with adherence to authority and conventional norms and values (Giger et al., 2016), with myths that legitimize a system of group-based hierarchy and discrimination (Giger et al., 2016; Jankowski, et al., 2011), and with belief in a just world (Giger et al., 2016). Moreover, the DVMAS has been shown to be correlated negatively with a proneness 
for empathetic responses and emotional concern (Giger, 2016). As with other ideologies involved in the maintenance of gender inequalities, men were shown to score higher on DVMAS than women (Giger et al., 2016; Jankowski et al., 2011; Lelaurain et al., 2018; Peters, 2008). Furthermore, predictive validity was also tested. Some contributions have highlighted the fact that the DVMAS was a significant predictor of the justification of abusive behaviors (i.e., perceived victim's responsibility, nonrecognition of violence, exoneration of the perpetrator; Giger et al., 2016; Lelaurain et al., 2018; Yamawaki, Ochoa-Shipp, Pulsipher, Harlos, \& Swindler, 2012) and that it was significantly correlated with perpetrating violence against a partner (Klaw et al., 2016).

Otherwise, the full scale has demonstrated good internal consistency. The various studies that used it reported $\alpha$ values between .81 and .88 (see Giger et al., 2016; Jankowski et al., 2011; Peters, 2008). But despite the theoretical consistency of the four dimensions of the DVMAS, factor analysis results from different studies using the same sample have consistently revealed an unstable structure (e.g., cross-loading of several items, five or four factors found; Jankowski et al., 2011; Peters, 2003, 2008). Therefore, Peters (2003) recommends using the total scale and emphasizes that before future research are conducted to establish its validity and reliability, the DVMAS should be used with caution. In this perspective, the question of the unidimensionality or multidimensionality of the DVMAS remains an open question in which we will try to answer in the French context. Beyond the study of its structure and psychometric qualities, the validation of the DVMAS in the French context also refers to an important issue related to the production of additional evidence allowing cultural generalization (see Hoyt, Warbasse, \& Chu, 2006).

\section{Overview}

This work aimed to validate the French version of the DVMAS. In accordance with the methodological strategy adopted in the previous validations of the DVMAS (Giger et al., 2016; Peters, 2008), we explored different psychometric qualities of this construct through several research operations (see Table 1). Such methodological choice is justified by the fact that it makes it possible to increase the generalizability of our results in the French population and to verify the constancy of the psychometric qualities related to the validation (i.e., external validity). In Study 1, the objectives were to test the structure of the DVMAS in the French context with a student population. In Study 2, we verified the consistency of the results obtained in Study 1 with a general population. We also aimed to examine convergent and discriminant validity of the external structure through the relationship between the DVMAS and other constructs, such as gender-specific system justification, ambivalent sexism, belief in a just world, and social desirability. In Study 3, we tested the predictive validity of the DVMAS with a general population by determining whether those who endorsed more IPV myths also exonerated the aggressor more, placed more responsibility on the victim of IPV, and perceived the violence as less severe. Ethical approval of the research was obtained from the University Ethics Committee of Aix-Marseille University, France (number 2016-02-03-010).

\section{Study I}

Study 1 investigated the internal structure of the DVMAS by using a principal component analysis and a confirmatory factorial analysis (CFA). Exploratory factor analysis (EFA) is a technique that highlights the structure of a set of variables while condensing the information contained within a large number of variables. The principle of CFA is to verify that the theoretical model is not different from the observed model (Long, 1983). More specifically, the matrix of covariances observed between items is compared to the matrix of covariances from the conceptual model. In order to verify this absence of difference, indicators are calculated to measure the quality of fit between the 
Table I. Synthesis of the Objectives, Methods, and Results of Each Study.

\begin{tabular}{lr}
\hline Objectives & Method \\
\hline Study I & \\
To test the internal structure of & Sample composed of students \\
the DVMAS in a French context & $(N=282)$. Use of a principal \\
& $\begin{array}{l}\text { component analysis and a } \\
\text { confirmatory factorial analysis }\end{array}$
\end{tabular}

Study 2

To verify the internal structure of the DVMAS and to examine convergent and discriminant validity of its external structure
Sample from the general population $(N=296)$. Use of a principal component analysis, a confirmatory factorial analysis, and correlational analysis
Results

- Results indicate a lack of discriminant validity of the internal structure of the DVMAS, which support a unidimensional structure of the construct

- Men endorsed significantly more myths than women

- Results reinforce the idea of a unidimensional structure of the construct

- The DVMAS is positively correlated with ambivalent sexism, gender-specific system justification, and belief in a just world, but it is not correlated with social desirability

- Men endorsed significantly more myths than women

\section{Study 3}

To test the predictive validity of Sample from the general population the DVMAS by exploring its relationship with the evaluation of an IPV situation
$(N=$ I56). Use of linear regression analysis
- Results showed that participants who endorsed more myths also placed more responsibility on the victim of IPV, exonerated the aggressor more, and perceived the violence as less severe

- Men rate the victim of IPV as more responsible than women

Note. DVMAS = Domestic Violence Myth Acceptance Scale; IPV = Intimate Partner Violence.

theoretical model and the observed model. All confirmatory factor analyses were carried out using AMOS (version 23). For the other analyses, we used SPSS (version 23).

\section{Method}

\section{Participants and Procedure}

Two hundred and eighty-two students (59.2\% women) aged between 18 and 34 years $(M=23.18$, $S D=4.16$ ) took part in the study. They were asked to report whether they knew victims of IPV (i.e., "Do you know any people who have been victims of IPV?") and if they had themselves been victims of IPV (i.e., "Have you ever been a victim of IPV?"). Twenty participants (7.1\%) reported having been a victim of IPV (18 of them were women), while 164 participants $(58.2 \%)$ said that they knew victims of IPV (96 of them were women). Participants were recruited in a French university via an online platform allowing student volunteers to take part in research conducted by university researchers. The research was presented as a study on gender relationship. Volunteers were informed 
Table 2. Internal Structure of the DVMAS in Studies I and 2.

\begin{tabular}{|c|c|c|c|c|c|c|c|c|c|c|}
\hline \multirow[b]{3}{*}{ Items } & \multicolumn{8}{|c|}{$\begin{array}{l}\text { PCA With Four Factors and Varimax Rotation } \\
\text { Factor Loadings Matrix }\end{array}$} & \multicolumn{2}{|c|}{$\begin{array}{c}\text { CFA With One Factor } \\
\text { Standardized Factor Loadings }\end{array}$} \\
\hline & \multicolumn{4}{|c|}{ Study I } & \multicolumn{4}{|c|}{ Study 2} & \multirow{2}{*}{$\frac{\text { Study I }}{\mathrm{FI}}$} & \multirow{2}{*}{$\frac{\text { Study } 2}{\mathrm{FI}}$} \\
\hline & $\mathrm{FI}$ & F2 & $\mathrm{F} 3$ & $\mathrm{~F} 4$ & $\mathrm{FI}$ & $\mathrm{F} 2$ & F3 & $\mathrm{F} 4$ & & \\
\hline 12 (BEH) & .67 & & & & .74 & & & & .51 & .51 \\
\hline $13(\mathrm{BEH})$ & .40 & .51 & & & .71 & & & & .60 & .50 \\
\hline 6 (BEH) & & .51 & & & .64 & & & & .50 & .62 \\
\hline 4 (BEH) & .63 & & & .33 & .60 & & & & .52 & .59 \\
\hline 17 (BEH) & & .79 & & & .50 & & & & .41 & .43 \\
\hline $10(\mathrm{CHA})$ & & .48 & .53 & & .50 & .42 & -.34 & & .60 & .40 \\
\hline $16(\mathrm{CHA})$ & & & .79 & & & .73 & & & .44 & .58 \\
\hline $3(\mathrm{CHA})$ & & .46 & .62 & & & .69 & & & .55 & .47 \\
\hline 7 (CHA) & & & .72 & & & .65 & & & .42 & .47 \\
\hline $18(\mathrm{CHA})$ & .56 & & .35 & & & .58 & & .35 & .43 & .51 \\
\hline $14(\mathrm{CHA})$ & .66 & .38 & & & & & & .86 & .56 & .48 \\
\hline $5(\mathrm{CHA})$ & .66 & .30 & & & & & & .84 & .54 & .48 \\
\hline I (MIN) & & & & .45 & & .55 & .37 & & .30 & .37 \\
\hline II (MIN) & & & & .67 & & .44 & .31 & & .20 & .48 \\
\hline $8(\mathrm{MIN})$ & & .32 & & .37 & & & .46 & & .41 & .49 \\
\hline 9 (EXO) & & & & .55 & & & .71 & & .49 & .48 \\
\hline 2 (EXO) & & & & .55 & & & .68 & & .46 & .58 \\
\hline 15 (EXO) & & & & .62 & & & .65 & & .52 & .62 \\
\hline Eigenvalue & 5.15 & 1.52 & 1.31 & 1.14 & 5.58 & 1.53 & 1.38 & 1.33 & $N / A$ & N/A \\
\hline Variance accounted (\%) & 28.60 & 8.43 & 7.26 & 6.34 & 31.0 & 8.50 & 7.68 & 7.39 & N/A & N/A \\
\hline
\end{tabular}

Note. Only saturations above .30 are presented for the PCA. PCA = principal component analysis; CFA = confirmatory factorial analysis; EXO = Exoneration of the Perpetrator; $\mathrm{CHAR}=$ Character Blame of the Victim; $\mathrm{BEH}=$ Behavior Blame of the Victim; MIN = Minimization of the Seriousness and Extent of the Abuse; DVMAS = Domestic Violence Myth Acceptance Scale.

that the study was anonymous and confidential. Thus, participants' identities could not be revealed through the collected data. They were also informed that they could refuse to participate and that they could stop at any time without any explanation and consequences. A questionnaire was given to participants only after receiving their consent. A debriefing was offered to participants after completion.

The first step of the validation consisted of translating the 18 items of the DVMAS into French, which was achieved using a forward- and back-translation procedure. Two English-language specialists were contacted. The initial version of the DVMAS was firstly translated from English into French. Then, a different translator carried out a blind reverse translation (i.e., from French to English). Finally, the two English versions were compared in order to verify the accuracy of the French version. To test the participants' understanding of the items and the overall assessment of the scale, a pretest was carried out with 15 people. This did not result in the modification of any items.

\section{Results}

\section{Exploratory Factor Analysis}

A PCA with four factors and Varimax rotation was performed with the 18-item DVMAS to check a potential four-factor structure (Table 2). The Kaiser-Meyer-Olkin measure of sampling adequacy 
Table 3. Goodness-of-Fit Statistics of the Three Tested Models in Studies I and 2.

\begin{tabular}{lcccccc}
\hline Models & $\chi^{2}(\mathrm{df})$ & $\chi^{2} / d f$ & RMSEA & TLI & CFI & AIC \\
\hline Without covariances (SI) & & & & & & \\
$\quad$ Model I: Four factors & $347.79(129)^{* * * *}$ & 2.70 & .078 & .74 & .81 & 467.79 \\
$\quad$ Model 2: One factor & $421.97(135)^{* * * *}$ & 3.13 & .087 & .68 & .74 & 529.97 \\
With covariances (SI) & & & & & & \\
$\quad$ Model I: Four factors & $272.27(124)^{* * * *}$ & 2.20 & .065 & .82 & .87 & 402.27 \\
$\quad$ Model 2: One factor & $310.31(130)^{* * * *}$ & 2.39 & .070 & .80 & .84 & 428.31 \\
With covariances (S2) & & & & & & \\
$\quad$ Model I: Four factors & $262.03(124)^{* * * *}$ & 2.11 & .045 & .88 & .92 & 392.03 \\
Model 2: One factor & $348.06(130)^{* * * *}$ & 2.68 & .056 & .82 & .87 & 466.06 \\
\hline
\end{tabular}

Note. Models "with covariances" correspond to those with paths between Items 3-10, Items 4-12, Items 5-14, Items 9-15, and Items I6-18. SI = Study I; S2 = Study 2; RMSEA = root-mean-square error of approximation; TLI = Tucker-Lewis index; $\mathrm{CFI}=$ comparative fit index; $\mathrm{AIC}=$ Akaike information criterion.

$* * * p<.001$.

indicated the satisfactory factorability of the correlation matrix $(\mathrm{KMO}=.84)$. The four factors accounted for $50.62 \%$ of the total variance. Examination of the factorial solution revealed that 10 items of the 18 presented high loading on more than one factor (i.e., saturation above .30), items supposed to belong to different factors loaded on the same factor (e.g., items related to Minimization of the abuse and Exoneration of the perpetrator loaded on Factor 4), and the scree plot suggested a potential two-factor structure. This problem was similar to that encountered in previous DVMAS validations. These patterns of results support a unidimensional structure.

\section{Confirmatory Factor Analyses}

In order to extend the factor structure of the DVMAS, we used CFA testing two models: Model 1 that was based on Peters's initial validation, which has four factors and 18 items; and Model 2 that examined a one-factor structure with the 18 items as suggested by Giger, Gonçalves, and Almeida (2016). We used several fit indices to determine the overall fit of the models. These included $\chi^{2}$, root-mean-square error of approximation (RMSEA), the Tucker-Lewis index (TLI), the comparative fit index (CFI), and the Akaike information criterion (AIC). An acceptable model fit is indicated by a CFI and TLI from .80 to .90; a good model fit is indicated by a CFI and TLI greater than .90, RMSEA lower than .08 (see Bentler, 1992; Browne \& Cudeck, 1993; Steiger, 2007), and AIC with the lowest possible value.

Goodness-of-fit statistics from the confirmatory factor analysis of each tested model are presented in Table 3. Results revealed that Models 1 and 2 did not fit the observed data well. Based on the Portuguese validation of the DVMAS (Giger et al., 2016), we rectified our models taking into account residual covariance of items with significant relationship between the error variances (which is also recommended by Floyd \& Widaman, 1995; Kline, 2011). We therefore drew paths between Items 3 and 10, Items 4 and 12, Items 9 and 15, Items 5 and 14, and Items 16 and 18 (Items of each pair are very close in meaning). The integration of these covariances improved the goodness of fit of Models 1 and 2. Both models have an acceptable fit with respect to the thresholds recommended in the literature. As Table 4 shows, all factors of Model 1 were significantly and strongly correlated with each other (all $p \mathrm{~s}<.001$ ). Two of these correlations were greater than .80 , which indicates a lack of discriminant validity of the internal structure of the construct (see Brown, 2006) strengthening the idea of a unidimensional structure. Standardized factor loadings of the one-factor model (Table 2) were all good except for Item 11 which fell below the minimum acceptable cutoff 
Table 4. Correlations Between the Four Factors of the DVMAS in Studies I and 2.

\begin{tabular}{lcccc}
\hline & \multicolumn{4}{c}{ Correlations } \\
\cline { 2 - 5 } Factors of the DVMAS & 1 & 2 & 3 & 4 \\
\hline I. Minimization of the abuse & - & $.81^{* * *}$ & $.78^{* * *}$ & $.65^{* * * *}$ \\
2. Exoneration of the perpetrator & $.75^{* * *}$ & - & $.76^{* * *}$ & $.65^{* * *}$ \\
3. Behavior blame & $.76^{* * *}$ & $.70^{* * *}$ & - & $.81^{* * *}$ \\
4. Character blame & $.81^{* * *}$ & $.62^{* * *}$ & $.64^{* * *}$ & - \\
\hline
\end{tabular}

Note. The results from Study I are presented above the diagonal, those from Study 2 below the diagonal. DVMAS = Domestic Violence Myth Acceptance Scale.

$* * * p<.001$.

Table 5. Comparisons Between Men and Women for Each Variable in Studies I and 2.

\begin{tabular}{|c|c|c|c|c|c|c|}
\hline \multirow[b]{2}{*}{ Variables } & \multicolumn{2}{|c|}{ Study I } & \multirow[b]{2}{*}{$t$} & \multicolumn{2}{|c|}{ Study 2} & \multirow[b]{2}{*}{$t$} \\
\hline & $\begin{array}{l}\text { Women } \\
M(S D)\end{array}$ & $\begin{array}{c}\text { Men } \\
M(S D)\end{array}$ & & $\begin{array}{l}\text { Women } \\
M(S D)\end{array}$ & $\begin{array}{c}\text { Men } \\
M(S D)\end{array}$ & \\
\hline DVMA & $2.62(0.86)$ & $3.12(0.87)$ & $4.77 * * *$ & $2.15(0.73)$ & $2.82(0.93)$ & $4.95 * * *$ \\
\hline ASI & & & & $1.06(1.06)$ & $1.87(1.05)$ & $4.13^{* * *}$ \\
\hline BS & & & & $1.27(1.15)$ & $1.61(1.32)$ & $2.00 *$ \\
\hline $\mathrm{HS}$ & & & & $1.17(1.15)$ & $2.13(1.31)$ & $5.39 * * *$ \\
\hline GSSJS & & & & 2.39 (I.24.) & $3.51(1.55)$ & $4.96 * * *$ \\
\hline BJW & & & & $2.27(0.82)$ & $2.49(0.89)$ & 1.74 \\
\hline
\end{tabular}

Note. DVMA = Domestic Violence Myth Acceptance; ASI = Ambivalent Sexism Inventory; BS = Benevolent Sexism; HS = Hostile Sexism; GSSJS = Gender-Specific System Justification Scale; BJW = Belief in a Just World.

$*_{p}<.05 . * * p<.001 . * * * p<.001$.

recommended in the literature of .30 (see Brown, 2006). However, it seems important to retain Item 11 insofar as it is the only one that refers to the perception of the extent of IPV in one's own living environment (i.e., "Domestic violence rarely happens in my neighborhood"). This is an important aspect of IPV minimization that should be maintained in the assessment of legitimizing myths, in which violence against women is often socially distanced.

\section{Reliability of Dimensions and Means Comparison}

Analyses for internal consistency (homogeneity) were performed using Cronbach's $\alpha$ coefficient. The reliability for the overall scale was good and consistent with previous studies $(\alpha=.85)$. Then, we examined whether the DVMAS could highlight the gender differences found in the literature (Table 5). This procedure also enabled the validity of the scale to be assessed. Indeed, an instrument which demonstrated evidence of reliability is assumed to highlight differences between two groups of participants for which we expect distinct scores (Trochim, as cited in Verniers \& Martinot, 2015). As expected, the overall DVMAS score was higher for men than for women $(p<.001)$.

\section{Study 2}

Study 2 aimed to generalize the findings of Study 1 by confirming the factor structure of the DVMAS with a more general population and to examine the convergent and discriminant validity of the external structure of the scale. Concerning convergent validity, as we have seen, domestic 
violence myths were shown to be associated with negative attitudes toward women and traditional gender role stereotypes (Jankowski et al., 2011; Peters, 2008). Two constructs measuring ideologies legitimizing patriarchy seemed particularly relevant for highlighting this link in the French version: ambivalent sexism and gender-specific system justification.

The first construct brings together two coexisting forms of sexism whose function seems to be the maintenance of women in their gender role as well as the legitimization of inequalities between men and women (Glick \& Fiske, 2001). On the one hand, benevolent sexism is defined as "a set of interrelated attitudes toward women that are sexist in terms of viewing women stereotypically and in restricted roles but that are subjectively positive in tone of feeling" (Glick \& Fiske, 1996, p. 491). On the other hand, hostile sexism is "based on masculine domination and superiority ideology and on a form of hostile sexuality" (Dardenne, Delacollette, Grégoire, \& Lecocq, 2006, p. 236). It is the bestknown form of sexism which is manifested for instance by sexual harassment or sexist remarks. Several studies have assessed the effect of ambivalent sexism on violence against women. For instance, Abrams, Viki, Masser, and Bohner (2003) showed that participants with a higher score of benevolent sexism blamed a rape victim who had "inappropriate" gender-role behavior significantly more than those with a lower score. Furthermore, hostile sexism significantly predicted the justification of IPV episodes (Expósito, Moya, \& Valor-Segura, 2004), particularly after a betrayal by the victim (Forbers, Jobe, White, Bloesch, \& Adams-Curtis, 2005).

The second construct regards gender-specific system justification. System justification (Jost \& Banaji, 1994) consists in supporting or defending the social, political, and economic structures as they are, by perceiving them as fair, natural, and unavoidable. Applied to gender inequalities, system justification is characterized by perceiving the current gender system as legitimate and justified. Several contributions have demonstrated the legitimizing function of gender stereotypes and sexist ideologies (Silván-Ferrero, del, \& López, 2007). Furthermore, a number of studies have highlighted the fact that system justification motivations participate in condemning and blaming victims of abuse. For instance, Ståhl, Eek, and Kazemi (2010) showed that participants with a higher score of system justification tended to blame a rape victim more than those with a lower score. The DVMAS should therefore be positively correlated with measures of ambivalent sexism and gender-specific system justification.

Peters (2008) suggested that domestic violence myths have a defensive function in that they protect people from the psychological threat of perceiving themselves as a potential victim or aggressor. In this regard, Giger et al. (2016) assumes that domestic violence myths function in a similar way to Lerner's (1980) notion of belief in a just world. This ideology considers that "individuals need to believe that they live in a world where people generally get what they deserve" (Lerner \& Miller, 1978, p. 1030). This notion suggests that we have control over our lives and the events that happen to us. Consequently, people "get what they deserve and deserve what they get" and victims are responsible for their own fate. Many studies based on belief in a just world have explained the negative attitudes against victims of different kinds of violence. Kleinke and Meyer (1990) highlighted the fact that male participants with a high belief in a just world judged a raped woman more negatively than those with a lower belief. In the same vein, Vonderhaar and Carmody (2015) showed that belief in a just world was linked to the adherence to rape myths. This legitimizing ideology was also associated with IPV justification in women who have a strong sense of belonging to the women's group (Correia, Alves, Morais, \& Ramos, 2015) as well as with victim blaming and exoneration of her abuser (Valor-Segura, Expósito, \& Moya, 2011). Accordingly, the DVMAS should be positively correlated with belief in a just world.

Concerning discriminant validity of the external structure, we tested the association of DVMAS with Social Desirability as Peters (2003) did in the initial version in order to control the possible contamination of the scale by social desirability. He expected that the DVMAS would not be correlated with it because myths do not have a social desirability function. However, the results 
showed a low but significant correlation between Social Desirability and DVMAS $(r=-.19$, $p<.01)$. This link no longer reached the level of significance with randomly selected subsamples of 40 participants, the minimum necessary to detect the desired effect (Cohen, as cited in Peters, 2003). The discriminant validity prediction of no significant correlation between Social Desirability and DVMAS was thus supported. Consequently, we expected the same result in our sample. Another way to test the discriminant validity of the DVMAS is to demonstrate that this scale is still linked to other legitimizing ideologies (i.e., ambivalent sexism, gender-specific system justification, and belief in a just world) once the effects of variables conceptually close to it have been controlled. This procedure allows testing if the DVMAS is not redundant with these other conceptually related constructs (see Duarte, Dambrun, \& Guimond, 2004; Verniers \& Martinot, 2015).

\section{Method}

\section{Participants and Procedure}

Two hundred and ninety-six participants ( $81.76 \%$ women) aged between 18 and 74 years $(M=32.23, S D=12.05)$ took part in the study. Three participants did not report their gender. Fifty-nine participants (19.9\%) reported having been a victim of IPV (52 of them were women), while 183 participants $(61.8 \%)$ said that they knew victims of IPV (155 of them were women). Participants were recruited on Facebook using snowball sampling, that is, by posting an advertisement on Facebook walls of acquaintances close to the researcher and inviting all respondents to share the post on their own wall. In this advertisement, the author presented herself as a researcher in Human and Social Sciences carrying out a study on gender relationships. It was also stated that it was possible to refuse to participate in this study or to stop at any time without any explanation and without consequences. Those who agreed to participate in this study, also presented as anonymous and confidential, were invited to click on the hyperlink that accompanied the ad to redirect them to the online questionnaire.

\section{Measures}

Our French version of DVMAS was used. Responses were given from 1 (strongly disagree) to 7 (strongly agree) and averaged such that higher overall scores represent stronger endorsement of myths surrounding IPV acceptance. The reliability of the overall score was good $(\alpha=.86)$.

The Ambivalent Sexism Inventory is a 22-item questionnaire which measures ambivalent sexism (Dardenne et al., 2006; Glick \& Fiske, 1996). This scale is composed of two subscales: Benevolent Sexism, which reflects a chivalrous ideology of being sympathetic and protective toward women who agree with conventional gender roles (e.g., "Many women have a quality of purity that few men possess"), and Hostile Sexism, which associates negative feelings toward women (e.g., "Once a woman gets a man to commit to her, she usually tries to put him on a tight leash"). Responses were given from 0 (strongly disagree) to 5 (strongly agree) and averaged such that higher scores represented a stronger endorsement of sexism. The reliability for the overall score was excellent $(\alpha=$ $.92)$, but also for benevolent $(\alpha=.90)$ and hostile $(\alpha=.94)$ sexisms.

Gender Specific System Justification Scale (Verniers \& Martinot, 2015) is an 8-item scale concerning equality between men and women in society and professional and private spheres (e.g., "The division of labor in families generally operates as it should"). Responses were given from 1 (strongly disagree) to 7 (strongly agree) and averaged such that higher scores represented stronger gender system justification. The reliability of the overall score was excellent $(\alpha=.93)$. 
Belief in a Just World Scale (Bègue \& Bastounis, 2003) is a 3-item questionnaire which measures belief in a just world (e.g., "I feel that a person's efforts are noticed and rewarded"). Responses were given on a 5-point Likert-type scale from 1 (strongly disagree) to 5 (strongly agree) and averaged such that higher scores represented stronger belief in the just world. The reliability of the overall score in our sample was good $(\alpha=.70)$.

The Social Desirability Scale (Cloutier, 1993; Crowne \& Marlowe, 1960) measures social desirability (e.g., "I have never deliberately said something that hurt someone's feelings"). Responses were given from 1 (strongly disagree) to 9 (strongly agree) and averaged such that higher scores represented stronger endorsement of social desirability. The reliability of the overall score was acceptable $(\alpha=.76)$.

\section{Results}

\section{Exploratory Factor Analysis}

In order to verify the problem of cross-loading on multiple factors, a PCA with four factors and Varimax rotation was once more performed with the 18-item DVMAS (Table 2). The measure of sampling adequacy indicated the satisfactory factorability of the correlation matrix $(\mathrm{KMO}=.84)$. The four factors accounted for $54.56 \%$ of the total variance Although several items presented high loading on more than one factor (i.e., saturation above .30), these saturations concerned half as many items as in Study 1 and the factor solution was generally closer to the theoretical structure than previously. However, we still observe the problem of items theoretically belonging to different factors (i.e., Minimization of the abuse and exoneration of the perpetrator) loading on the same factor. Moreover, the scree plot suggested a potential three-factor structure. These patterns of results reinforce the idea of a unidimensional structure.

\section{Confirmatory Factor Analyses}

In order to confirm the structure of domestic violence myths observed in Study 1, data were once more submitted to a CFA (Table 3). After taking into account residual covariances of items with relationship between the error variances, results showed a better goodness of fit than in Study 1 concerning Model 1 including the four-factor structure as well as Model 2 including the one-factor structure. Moreover, all factors of Model 1 were significantly correlated with each other (all $p$ s < .001 ; see Table 4). One of these correlations was greater than .80 , which indicated a lack of discriminant validity of the internal structure of the construct as observed in Study 1. Standardized factor loadings of the one-factor model (Table 2) ranged from .40 to .62. Note that the problem of low saturation of Item 11 observed in Study 1 was not repeated in Study 2 (standardized loading at .20 and .48 , respectively). This result thus confirms the need to maintain this item relating to the social distance in the French version of the DVMAS.

\section{Convergent Validity}

In accordance with our hypotheses, bivariate correlations showed that the DVMAS was positively correlated to Gender-Specific System Justification, Belief in a Just World, and Ambivalent Sexism and its two subscales (all $p \mathrm{~s}<.01$, Table 6 ). The correlation was stronger for Hostile Sexism $(p<$ $.01)$, than for Benevolent Sexism $(p<.01)$. Thus, the more participants adhered to Domestic Violence Myths, the more they adhered to ideologies legitimizing the social order. 
Table 6. Convergent and Discriminant Validity for the DVMAS in Study 2.

\begin{tabular}{lcccccc}
\hline Variables & 1 & 2 & 3 & 4 & 5 & 6 \\
\hline I. DVMAS & & & & & & \\
2. ASI & $.60^{* *}$ & & & & \\
3. SH & $.62^{* *}$ & $.92^{* *}$ & & & \\
4 SB & $.46^{* *}$ & $.90^{* *}$ & $.66^{* *}$ & & \\
5. GSS & $.52^{* *}$ & $.53^{* *}$ & $.60^{* *}$ & $.36^{* *}$ & & \\
6. BJW & $.49^{* *}$ & $.40^{* *}$ & $.40^{* *}$ & $.32^{* *}$ & $.46^{* *}$ & \\
7. SD & -.10 & $-.12^{*}$ & $-.13^{*}$ & -.08 & .02 & -.05
\end{tabular}

Note. DVMAS = Domestic Violence Myth Acceptance Scale; ASI = Ambivalent Sexism Inventory; BS = Benevolent Sexism; HS = Hostile Sexism; GSS = Gender-Specific System Justification; BJW = Belief in a Just World; SD = Social Desirability. $*_{p}<.05 . * * p<.01$.

\section{Discriminant Validity of the External Structure}

In order to test the discriminant validity of the DVMAS, we first tested correlations with social desirability. The results showed a nonsignificant correlation between the overall score of DVMAS and Social Desirability $(p=.09)$. The discriminant validity prediction was thus supported. Then, a series of partial correlations were carried out to examine whether adherence to Domestic Violence Myths was still linked to other legitimizing ideologies when the effect of conceptually related variables was controlled. A first partial correlation analysis highlighted the fact that the relationship between the DVMAS and Gender-Specific System Justification remained significant after controlling Belief in a Just World, $r(296)=.38, p<.01$, and Ambivalent Sexism, $r(296)=.30, p<.01$. Then, the correlation between the DVMAS and Belief in a Just World remained significant after controlling Gender-Specific System Justification, $r(296)=.33, p<.01$, and Ambivalent Sexism $(p<$ $.01)$. Finally, correlations between the DVMAS and Ambivalent Sexism remained significant after controlling Belief in a Just World, $r(296)=.51, p<.01$, and Gender-Specific System Justification, $r(296)=.45, p<.01$. These results indicate that DVMAS is related to others legitimizing ideologies without being redundant with them.

\section{Mean Comparisons}

In accordance with Study 1, the DVMAS score was higher for men than for women $(p<.001)$. In others words, men endorsed significantly more myths than women (Table 5).

\section{Study 3}

According to Peters (2008), domestic violence myths contribute to blaming the victim, exonerating the perpetrator, and minimizing the importance of IPV. They also reduce social support for survivors by transforming them from innocent victims to individuals who consciously or unconsciously cause abuse or desire to be abused. In line with these considerations, Study 3 tested the predictive validity of the DVMAS by determining whether men and women who endorsed more domestic violence myths also exonerate the aggressor more, consider the victim to be more responsible for the abuse, and perceive the violence as less severe. We adopted the same procedure here as in the Portuguese validation of the DVMAS (Giger et al., 2016). 


\section{Method}

\section{Participants and Procedure}

One hundred and fifty-six participants ( $51.3 \%$ women) aged between 18 and 74 years $(M=41.87$, $S D=15.36)$ took part in the study. Forty participants $(25.6 \%)$ reported having been a victim of IPV (30 of them were women), while 73 (46.8\%) said that they knew victims of IPV (43 of them were women). Participants were approached in various public places such as university libraries, train and bus stations, and main streets of a city in the south of France. The research was presented to participants as a questionnaire on couple relationships. They were informed about several instructions concerning the questionnaire they had to complete after receiving their consent. The questionnaire was presented as anonymous and confidential. It was made clear that they could refuse to participate and that they could stop at any time without any explanation and without any consequences. A debriefing was proposed to participants after completion.

Participants were asked to evaluate an IPV situation presented in a short scenario. This procedure was based on the scenario technique that confronts people with a fictitious situation which is however described in the most credible way possible (see Korn, 1997). In our case, this technique allowed participants to project themselves and imagine how they would react if faced with the described situation. In order to ensure comparability of the results with the literature, we translated the scenario used in the Portuguese validation of the DVMAS (Giger et al., 2016). This scenario showed Marie and Jean, a couple watching TV. Jean was suspicious following a phone call received by Marie to which she did not reply. He checked the call list on her cell phone, saw the name of a man, became angry, threw the cell phone against the wall (the mobile phone broke), grabbed her wrist with full force, and asked for information. Marie explained that it was a call from a colleague about a project they are working on. Jean accused Marie of creating problems, and then hugged her, and said he loved her.

\section{Data Collection}

The scenario was evaluated using a 12-item questionnaire measuring three subscales: the Perceived Responsibility of the Female Character (e.g., "Marie is responsible for the situation"), the Perceived Exoneration of the Male Character (e.g., "It is obvious that Jean loves Marie"), and the Perceived Severity of the Violence Perpetrated by the Male Character on the Female Character (e.g., "This experience will have psychologically damaged on Marie"). Responses were given from 1 (strongly disagree) to 7 (strongly agree) with higher scores representing higher victim responsibility, aggressor exoneration, and perceived violence severity. The reliability of the scores of the three subscales was excellent $(\alpha=.87$ to .91$)$.

We also used our French version of DVMAS. Responses were given from 1 (strongly disagree) to 7 (strongly agree) and averaged such that higher overall scores represent greater endorsement of myths surrounding IPV acceptance. The reliability of the overall score was good $(\alpha=.86)$.

\section{Results}

In order to examine the predictive power of the French DVMAS on the evaluation of the IPV situation, linear regressions analyses were performed (Table 7). In addition to the DVMAS, knowing a victim, participants' age, and gender were also included in the regression models as controlled variables. Results showed an adequate amount of variance for the prediction of Perceived Victim Responsibility, adjusted $R^{2}=.31, F(4,147)=17.6, p<.001$; Perceived Exoneration of Aggressor, adjusted $R^{2}=.24, F(4,147)=13.14, p<.001$; and Perceived Violence Severity, adjusted $R^{2}=.07$, $F(4,147)=4.02, p<.01$. The DVMAS were significant predictors of the three evaluations of the 
Table 7. Linear Regression Analyses for the Evaluation of the Intimate Partner Violence Situation in Study 3.

\begin{tabular}{|c|c|c|c|c|c|c|c|c|c|}
\hline \multirow[b]{2}{*}{ Variables } & \multicolumn{3}{|c|}{$\begin{array}{l}\text { Perceived Victim } \\
\text { Responsibility }\end{array}$} & \multicolumn{3}{|c|}{ Exoneration of Perpetrator } & \multicolumn{3}{|c|}{ Perceived Violence Severity } \\
\hline & B & $S E B$ & $\beta$ & B & SE B & $\beta$ & B & SE B & $\beta$ \\
\hline DVMAS & $.67 * * *$ & .10 & .50 & $.64 * * *$ & .11 & .45 & $-.33 * *$ & .11 & -.26 \\
\hline Age & .01 & .01 & .03 & -.01 & .01 & -.11 & -.01 & .01 & -.01 \\
\hline Gender & $-.50 *$ & .23 & -.14 & -.30 & .26 & -.09 & .14 & .26 & .05 \\
\hline Knowing a victim & .08 & .22 & .03 & -.12 & .24 & -.04 & -.39 & .24 & -.13 \\
\hline Model statistics & Adjusted $R$ & $\begin{array}{l}=.31 \\
17.6 * *\end{array}$ & $(4,147)$ & Adjusted & $\begin{array}{l}=.24, F \\
13.14 * * 2=\end{array}$ & 147) $=$ & Adjuste & $\begin{array}{l}2^{2}=.07 \\
=4.02^{2}\end{array}$ & $F(4,147)$ \\
\hline
\end{tabular}

Note. Gender $(\mathrm{I}=$ man, 2 = woman $)$. DVMAS = Domestic Violence Myth Acceptance Scale.

$*_{p}<.01$. ***p $<.001$.

IPV situation (all $p \mathrm{~s}<.002$ ). The controlled variables were nonsignificant in the prediction of evaluations, with the exception of gender that was a significant predictor of perceived victim responsibility $(p<.05)$. More specifically, men rate victim as more responsible than women.

\section{General Discussion}

This research aimed to validate and adapt the DVMAS for the French context in order by testing its structure and its convergent, discriminant, and predictive validities. The three studies showed that it is a suitable instrument for measuring legitimizing myths about violence perpetrated by men against women in intimate relationships. Although initially conceptualized as a four-dimensional scale (i.e., Character blame, Behavior blame, Minimization, and Exoneration), the DVMAS could also be better characterized as a one-dimensional scale (Peters, 2008). Indeed, the results showed that the multidimensional nature of this scale remains unclear and questionable as has already been shown in the literature. They also showed that the unidimensional version of the construct had an acceptable fit to the data among different French populations. This leads us to recommend the use of the French DVMAS with its one-factor version rather than with its four-factor version.

Concerning convergent and discriminant validity of the external structure, the French DVMAS was positively associated with belief in a just world and ambivalent sexism. Extending previous research, this scale was shown to be positively associated with gender-specific system justification showing that domestic violence myths acceptance could be another system-justifying ideology among the others already identified (for a review, see Jost \& Hunyady, 2002). Regarding discriminant validity, the results obtained using partial correlations reveal that the DVMAS is a measure that is not redundant with measures of ambivalent sexism, belief in a just world, and gender-specific system justification. Indeed, by statistically controlling for the effects of ambivalent sexism, belief in a just world, and gender-specific system, respectively, the link between DVMAS and these scales remained significant. In addition, our results highlighted the fact that the French version of the DVMAS had an appropriate predictive validity. Domestic violence myths were significant predictors of perceived victim responsibility, perceived aggressor responsibility, and perceived violence severity, even when gender, age, and knowing a victim were controlled. Finally, means comparisons carried out between men's and women's scores confirmed the validity of the scale and its capacity to detect the differences usually reported in the literature: men endorsed more domestic violence myths than women (Giger, 2016; Nayak, Byrne, Martìn, \& Abraham, 2003; Peters, 2008; Yamawaki et al., 2012; Yamawaki, Ostenson, \& Brown, 2009). 


\section{Strengths, Limitations, and Perspectives}

The results of this research bring additional evidence of the validity of the DVMAS in that it provides a contribution to its cultural generalizability (Hoyt et al., 2006). Results suggest the applicability of the construct of DVMAS in different cultural contexts, and therefore the utility of using this scale to assess the construct in cross-cultural studies. For instance, both our results and the literature show that the unidimensional version of the DVMAS is stable across the United States, France, and Portugal. Although these countries may be different, they seem to share a common background concerning ideologies legitimizing violence against women. However, the rate of violence found between these countries is not the same. The cross-national survey led by the European Union Agency for Fundamental Rights (2014) in order to assess violence perpetrated against women showed that in Portugal, between $10 \%$ and $19 \%$ of women have experienced physical and/or sexual violence from either a current or a previous partner, against $20 \%$ and $29 \%$ in France. This study also shows that women's perception of the frequency of violence against women was higher in France than in Portugal. Intercultural research using DVMAS could study how adherence to these myths and their impact on violence legitimization and perpetration varies across countries in order to better understand these differences. In addition, cultural generalizability should be tested by future research by comparing more diverse cultures.

This work has several limitations that should be considered. Firstly, although we used heterogeneous samples across the three studies that show stability in our results, they were convenience samples. Indeed, data collections were based on nonprobabilistic sampling, which limits the generalization of the results. Thus, it would be relevant to study a sample representative of the general population. On the other hand, studies with more specific populations, such as perpetrators or survivors, would also be useful to compare whether adherence to myths varies among them. For instance, it could be interesting to analyze the association between adherence to violence perpetration and domestic violence myths among men as recommended by Megías, Toro-García, and Carretero-Dios (2018).

A second limitation lies in the fact that the results were all based on correlational data. Therefore, it invites us to be cautious when interpreting and generalizing the findings since further research is needed. In this perspective, it could be relevant to use another methodological approach in order to extend our knowledge of the causes and consequences associated with a higher endorsement of myths about IPV. It could be relevant to use experimental procedures in order to analyze more closely the way in which adherence to domestic violence myths can be regulated according to social context. For instance, it would be interesting to manipulate different situational characteristics of the victim or the perpetrator in order to study the possible moderating role of these myths in the perception of IPV according to social context. A third limitation concerns the use of the term "IPV" in our items to ask people if they were a victim of IPV or if they witnessed it. Asking directly about "IPV" may have resulted in undercounting victims, since some survivors may not label what they have experienced as "violence" or "abuse." It would rather have been relevant to ask about specific behaviors (e.g., "Has your male partner ever slapped, hit, or punched you?"). Finally, a fourth limitation regards the specificity of the scenario used in Study 3, which is not representative of all cases that may involve IPV. From this perspective, we should analyze how adherence to these myths impacts the assessment of different types of violence in different social contexts.

Future research should finally focus more specifically on the potential differences between men and women in the structure of the DVMAS. For instance, Peters (2003) showed that this construct had different factor structures according to gender, which suggests that men and women might interpret items differently because of distinct motivations for adhering to myths legitimizing IPV. However, this difference has never been confirmed in the context of CFA. This work would make it 
possible to decide on the variance or structural invariance of the DVMAS, but also to explore the consequences of this structure on the way each sex perceives and evaluates IPV situations.

\section{Practice Implications}

Understanding how stereotypical and negative beliefs about IPV are constructed and spread in a social space is an important issue since they are always likely to maintain a societal climate that encourages this kind of violence (Archer \& Graham-Kevan, 2003; Capezza \& Arriaga, 2008). More specifically, they contribute to the nonrecognition or acceptance of IPV and they affect judgments toward victims (Baldry \& Pagliaro, 2014). For instance, they reduce social support for survivors and play a major role in the response to this violence and in the way they deal with it (Flood \& Pease, 2009). In addition, these attitudes influence perpetrators' behaviors:

in a community where a higher proportion of the general population feels that IPV is justifiable, a potential perpetrator will be more likely to feel he or she has the right, should the cause arise. This perception of increased right would result in an increased incidence of perpetration. (Waltermaurer, 2012, p. 167)

Domestic violence myths are part of these beliefs that impact the recognition of IPV. Therefore, it seems crucial to have tools which demonstrated reliability and validity to measure them. At a practical level, the DVMAS could be used to identify and assess the extent and pervasiveness of IPV myths in different populations. For instance, our results revealed that participants who knew victims of IPV were less likely to endorse myths than others, which is consistent with some of the studies by Giger et al. (2016). The DVMAS could also be integrated into prevention program evaluation aimed at reducing prejudices and stereotypes against IPV, from a perspective of assessing individual and group attitudes. For instance, it could be used to assess the efficacy of these programs in modifying negative and stereotypical attitudes underlying IPV. However, these awareness-raising measures should not only be directed toward the general public, since professionals likely to support victims are also influenced by these socially shaped norms and values which contribute to the nonrecognition of IPV (see Thapar-Björkert \& Morgan, 2010). For instance, Wandrei and Rupert (2000) highlighted the fact that psychologists can hold a victim more responsible for the violence if she reported having experienced a violent relationship in the past. In the same vein, police officers consider a victim who drank alcohol to be more accountable than one who did not (Stewart \& Madden, 1997). Therefore, setting up specific professional training aimed at deconstructing these myths that help to legitimize IPV is a real issue, in order to ensure more appropriate assistance to victims. From this perspective, the DVMAS could act as a guide for the development of content in these programs.

Finally, consistent with other studies, our results show that domestic violence myth acceptance was associated with a set of belief systems at work in the maintenance of the social hierarchy between genders. They are not isolated beliefs but are shaped by a larger framework, implicated in the justification of a system of gender oppression and, ultimately, the persistence of IPV. Thus, a measure such as DVMAS could help counteract the trend of seeing IPV as arising essentially from personal and interpersonal factors (e.g., psychopathologies, family, and couple problems) and thus promote a focus on the social and structural aspects of IPV, in the development of programs, policies, and educational campaigns in France (Hernandez Orellana \& Kunert, 2014). Examining and addressing IPV as a gender-based issue appears essential in order to make progress in reducing this highly prevalent and impactful form of abuse (Reed, Raj, Miller, \& Silverman, 2010). 


\section{Appendix}

\section{French Version of the DVMAS}

Instruction: Indiquez dans quelle mesure vous êtes d'accord ou pas d'accord avec chacun des énoncés en utilisant la notation suivante: 1 (pas du tout d'accord) à 7 (tout à fait d'accord).

1. La violence conjugale affecte peu de gens [Domestic violence does not affect many people] (MIN)

2. Lorsqu'un un homme est violent, c'est qu'il a perdu son sang froid [When a man is violent, it is because he lost control of his temper] (EXO)

3. Si une femme continue à vivre avec un homme qui la maltraite, c'est de sa faute si elle est à nouveau maltraitée [If a woman continues living with a man who beats her, then it is her own fault if she is beaten again] (PERS)

4. Rendre un homme jaloux, c'est chercher des ennuis [Making a man jealous is asking for it] (COMP)

5. Certaines femmes veulent inconsciemment que leurs conjoints les dominent [Some women unconsciously want their partners to control them] (PERS)

6. Beaucoup de violences conjugales ont lieu parce que les femmes n'arrêtent pas de se disputer avec leurs conjoints [A lot of domestic violence occurs because women keep on arguing about things with their partners] (COMP)

7. Si une femme n'est pas contente, elle n'a qu'à partir [If a woman doesn't like it, she can leave] (PERS)

8. La plupart des violences conjugales impliquent de la violence réciproque entre conjoints [Most domestic violence involves mutual violence between the partners] (MIN)

9. Les hommes violents perdent tellement le contrôle qu'ils ne savent pas ce qu'ils font [Abusive men lose control so much that they don't know what they're doing] (EXO)

10. Je regrette de le dire, mais si une femme reste avec un homme qui la maltraite, au fond elle mérite ce qu'il lui arrive [I hate to say it, but if a woman stays with the man who abused her, she basically deserves what she gets] (PERS)

11. Il y a peu de cas de violences conjugales dans mon quartier [Domestic violence rarely happens in my neighborhood] (MIN)

12. Les femmes qui flirtent cherchent des ennuis [Women who flirt are asking for it] (COMP)

13. Les femmes peuvent éviter les violences si elles cessent de s'opposer de temps en temps [Women can avoid physical abuse if they give in occasionally] (COMP)

14. Beaucoup de femmes souhaitent inconsciemment être contrôlées par leurs conjoints [Many women have an unconscious wish to be dominated by their partners] (PERS)

15. La violence conjugale résulte d'une perte de contrôle momentanée [Domestic violence results from a momentary loss of temper] (EXO)

16. J'ai du mal à comprendre une femme maltraitée qui retourne sans cesse vers son partenaire [I don't have much sympathy for a battered woman who keeps going back to the abuser] (PERS)

17. Les femmes sont responsables de la plupart des violences conjugales [Women instigate most family violence] (COMP)

18. Si une femme retourne vers son partenaire violent, c'est lié à sa personnalité [If a woman goes back to the abuser, how much is that due to something in her character?] (PERS) 


\section{Nota Bene}

EXO = Exonération de l'agresseur; PERS = Condamnation de la personnalité de la victime; $\mathrm{COMP}=$ Condamnation du comportement de la victime; MIN = Minimisation de la gravité et de l'ampleur des violences.

\section{Acknowledgments}

The authors wish to thank the three reviewers for their comments which allowed to improve the relevance of this article.

\section{Declaration of Conflicting Interests}

The author(s) declared no potential conflicts of interest with respect to the research, authorship, and/or publication of this article.

\section{Funding}

The author(s) received no financial support for the research, authorship, and/or publication of this article.

\section{References}

Abrams, D., Viki, G. T., Masser, B., \& Bohner, G. (2003). Perceptions of stranger and acquaintance rape: The role of benevolent and hostile sexism in victim blame and rape proclivity. Journal of Personality and Social Psychology, 84, 111-125. doi:10.1037/0022-3514.84.1.111

Archer, J., \& Graham-Kevan, N. (2003). Do beliefs about aggression predict physical aggression of partner? Aggressive Behavior, 29, 41-54. doi:10.1002/ab.10029

Baldry, A. C., \& Pagliaro, S. (2014). Helping victims of intimate partner violence: The influence of group norms among lay people and the police. Psychology of Violence, 4, 334-347. doi:10.1037/t05289-000

Bauer, A., \& Soullez, C. (2012). La criminalité en France. Rapport 2012 de l'Observatoire National de la Délinquance et des Réponses Pénales [Criminality in France. 2012 Report of the National Observatory of Delinquency and Penal Responses]. Retrieved from http://www.inhesj.fr/sites/default/files/files/Synthese_ Rapport_ONDRP_2012.pdf

Bègue, L., \& Bastounis, M. (2003). Two spheres of belief in justice: Extensive support for the bidimensional model of belief in a just world. Journal of Personality, 71, 435-463. doi:10.1111/1467-6494.7103007

Bentler, P. M. (1992). On the fit of models to covariances and methodology to the Bulletin. Psychological Bulletin, 112, 400-404. doi:10.1037/0033-2909.112.3.400

Bohner, G. (1998). Vergewaltigungsmythen: Sozialpsychologische untersuchungen über täterentlastende und opferfeindliche überzeugungen im bereich sexueller gewalt [Rape myths: Social-psychological studies about beliefs that exonerate perpetrators and blame the victim of sexual violence]. Landau, Germany: Verlag Empirische Pädagogik.

Bograd, M. (1990). Feminist perspectives on wife abuse: An introduction. In K. Yllö \& M. Bograd (Eds.), Feminist perspectives on wife abuse (pp. 11-26). Newbury Park, CA: Sage.

Brown, T. A. (2006). Confirmatory factor analysis for applied research. New York, NY: Guilford Press.

Browne, M. W., \& Cudeck, R. (1993). Alternative ways of assessing model fit. In K. A. Bollen \& J. S. Long (Eds.), Testing structural equation models (pp. 136-162). London, England: Sage.

Burger, J. M. (1981). Motivational biases in the attribution of responsibility for an accident: A meta-analysis of the defensive-attribution hypothesis. Psychological Bulletin, 90, 496-512. doi:10.1037/0033-2909.90.3.496

Burt, M. R. (1980). Cultural myths and supports for rape. Journal of Personality and Social Psychology, 38, 217-230. doi:10.1037/0022-3514.38.2.217

Capezza, N. M., \& Arriaga, X. B. (2008). Factors associated with acceptance of psychological aggression against women. Violence Against Women, 14, 612-633. doi:10.1177/1077801208319004. 
Cloutier, J. (1993). La désirabilité sociale chez les agresseurs sexuels [Social desirability among sex offenders]. Mémoire de maitrise. Montréal, Québec: Université de Montréal.

Correia, I., Alves, H., Morais, R., \& Ramos, M. (2015). The legitimation of wife abuse among women: The impact of belief in a just world and gender identification. Personality and Individual Differences, 767-712. doi:10.1016/j.paid.2014.11.041

Crowne, D. P., \& Marlowe, D. (1960). A new scale of social desirability independent of psychopathology. Journal of Consulting Psychology, 24, 349-354. doi:10.1037/h0047358

Dardenne, B., Delacollette, N., Grégoire, C., \& Lecocq, D. (2006). Structure latente et validation de la version française de l'Ambivalent Sexism Inventory: L'échelle de sexisme ambivalent [Latent structure and validation of the French version of Ambivalent Sexism Inventory: The scale of ambivalent sexism]. L'Année Psychologique, 106, 235-264. doi:10.4074/S0003503306002041

Dobash, R. P., Dobash, R. E., Wilson, M., \& Daly, M. (1992). The myth of sexual symmetry in marital violence. Social Problems, 39, 71-85. doi:10.1525/sp.1992.39.1.03x0064 1

Duarte, S., Dambrun, M., \& Guimond, S. (2004). La dominance sociale et les “mythes légitimateurs": Validation d'une version française de l'échelle d'orientation à la dominance sociale [Social dominance and legitimizing myths: Validation of a French form of the Social Dominance Orientation scale.] Revue Internationale de Psychologie Sociale, 17, 97-126.

European Union Agency for Fundamental Rights. (2014). Violence against women: An EU-wide survey. Luxembourg City, Luxembourg: Publications Office of the European Union. Retrieved from http://fra. europa.eu/sites/default/files/fra-2014-vaw-survey-main-results-apr14_en.pdf

Expósito, F., Moya, M., \& Valor-Segura, I. (2004). Variables situaciones que influyen en la percepción de situaciones de violencia domestica [Variables that influence the perception of situations of domestic violence]. 5th Congreso de la SEPEX (Sociedad Española de Psicologia Experimental), Madrid, Marzo.

Flood, M., \& Pease, B. (2009). Factors influencing attitudes to violence against women. Trauma, Violence, \& Abuse, 10, 125-142. doi:10.1177/1524838009334131

Floyd, F. J., \& Widaman, K. F. (1995). Factor analysis in the development and refinement of clinical assessment instruments. Psychological Assessment, 7, 286-299. doi:10.1037/1040-3590.7.3.286

Forbers, G. B., Jobe, R. L., White, K. B., Bloesch, E., \& Adams-Curtis, L. E. (2005). Perceptions of dating violence following a sexual or nonsexual betrayal of trust: Effects of gender, sexism, acceptance of rape myths, and vengeance motivation. Sex Roles, 52, 165-173. doi:10.1007/s11199-005-1292-6

Garcia-Moreno, C., Jansen, H. M., Ellsberg, M., Heise, L., \& Watts, C. H. (2006). Prevalence of intimate partner violence: Findings from the WHO multi-country study on women's health and domestic violence. The Lancet, 368, 1260-1269. doi:10.1016/S0140-6736(06)69523-8

Giger, J. C., Gonçalves, G., \& Almeida, S. A. (2016). Adaptation of the domestic violence myth acceptance scale to Portuguese and tests of its convergent, divergent, and predictive validities. Violence Against Women. Advance online publication. doi:10.1177/1077801216666724

Glick, P., \& Fiske, S. T. (1996). The ambivalent sexism inventory: Differentiating hostile and benevolent sexism. Journal of Personality and Social Psychology, 70, 491-512. doi:10.1037/0022-3514.70.3.491

Glick, P., \& Fiske, S. T. (2001). Ambivalent stereotypes as legitimizing ideologies: Differentiating paternalistic and envious prejudice. In J. T. Jost \& B. Major (Eds.), The psychology of legitimacy. Emerging perspectives on ideology, justice, and intergroup relations (pp. 278-306). Cambridge, England: Cambridge University Press.

Hernandez Orellana, M., \& Kunert, S. (2014). Quand l'État parle des violences faites aux femmes [When the state talks about violence against women]. Lussaud, France: Fontenay-le-Comte.

Hoyt, W. T., Warbasse, R. E., \& Chu, E. Y. (2006). Construct validation in counseling psychology research. The Counseling Psychologist, 34, 769-805. doi:10.1177/0011000006287389

Hunnicutt, G. (2009). Varieties of patriarchy and violence against women resurrecting "patriarchy" as a theoretical tool. Violence Against Women, 15, 553-573. doi:10.1177/1077801208331246 
Jankowski, P. J., Johnson, A. J., Holtz Damron, J. E., \& Smischney, T. (2011). Religiosity, intolerant attitudes, and domestic violence myth acceptance. International Journal for the Psychology of Religion, 21, 163-182. doi:10.1080/10508619.2011.581574

Jaspard, M., Brown, E., Condon, S., Fougeyrollas-Schwebel, D., Houel, A., Lhomond, B., ... Schiltz, MA. (2003). Les violences envers les femmes en France, une enquête nationale [Violence against women in France, a national survey]. Paris, France: Documentation Française.

Jost, J. T., \& Banaji, M. R. (1994). The role of stereotyping in system-justification and the production of false consciousness. British Journal of Social Psychology, 33, 1-27. doi:10.1111/j.2044-8309.1994.tb01008.x

Jost, J. T., \& Hunyady, O. (2002). The psychology of system justification and the palliative function of ideology. European Review of Social Psychology, 13, 111-153.

Klaw, E. L., Demers, A. L., \& Da Silva, N. (2016). Predicting risk factors for intimate partner violence among post-9/11 college student veterans. Journal of Interpersonal Violence, 31, 572-592. doi:10.1177/ 0886260514556102

Kleinke, C. L., \& Meyer, C. (1990). Evaluation of rape victims by men and women with high and low belief in a just world. Psychology of Women Quarterly, 14, 243-253. doi:10.1111/j.1471-6402.1990.tb00024.x

Kline, R. (2011). Principles and practice of structural equation modeling. New York, NY: Guilford Press.

Korn, J. H. (1997). Illusions of reality: A history of deception in social psychology. Albany: State University of New York Press.

Lelaurain, S., Fonte, D., Aim, M. A., Khatmi, N., Decarsin, T., Lo Monaco, G., \& Apostolidis, T. (2018). “One doesn't slap a girl but..." Social representations and conditional logics in legitimization of intimate partner violence. Sex Roles, 78, 637-652. doi:10.1007/s11199-017-0821-4

Lelaurain, S., Graziani, P., \& Lo Monaco, G. (2017). Intimate partner violence and help-seeking: A systematic review and social psychological tracks to future research. European Psychologist. Advance online publication. doi:10.1027/1016-9040/a000304

Lerner, M. J. (1980). The belief in a just world: A fundamental delusion. New York, NY: Plenum Press.

Lerner, M. J., \& Miller, D. T. (1978). Just world research and the attribution process: Looking back and ahead. Psychological Bulletin, 85, 1030-1051. doi:10.1037/0033-2909.85.5.1030

Liang, B., Goodman, L., Tummala-Narra, P., \& Weintraub, S. (2005). A theoretical framework for understanding help-seeking processes among survivors of intimate partner violence. American Journal of Community Psychology, 36, 71-84. doi:10.1007/s10464-005-6233-6

Long, S. J. (1983). Confirmatory factor analysis. Beverly Hills, CA: Sage.

Megías, J. L., Toro-García, V., \& Carretero-Dios, H. (2018). The Acceptance of Myths About Intimate Partner Violence Against Women (AMIVAW) Scale: Development and validation in Spanish and English. Psychology of Women Quarterly, 42, 44-61. doi:10.1177/0361684317742638

Meyer, L., McConnell, J., Fensham, L., Groth, L., Jansen, R., \& Phillips, V. (2007). Assessment of the implementation of the domestic violence act and its effects on the lives of women seeking protection orders-A study of abused women at four courts in eThekwini. Pretoria, South Africa: Lawyers for Human Rights.

Montalvo-Liendo, N. (2009). Cross-cultural factors in disclosure of intimate partner violence: An integrated review. Journal of Advanced Nursing, 65, 20-34.

Morin, T., Jaluzot, L., \& Picard, S. (2013). Femmes et hommes face à la violence /Women and men facing violence]. Retrieved from http://www.insee.fr/fr/ffc/ipweb/ip1473/ip1473.pdf

Nayak, M. B., Byrne, C. A., Martìn, M. K., \& Abraham, A. G. (2003). Attitudes toward violence against women: A cross-national study. Sex Roles, 49, 333-342. doi:10.1023/A:1025108103617

Peters, J. (2003). The domestic violence myth acceptance scale: Development and psychometric testing of a new instrument. Dissertation Abstracts International Section A, 64, 1409.

Peters, J. (2008). Measuring myths about domestic violence: Development and initial validation of the domestic violence myth acceptance scale. Journal of Aggression, Maltreatment \& Trauma, 16, 1-21. doi:10.1080/ 10926770801917780 
Policastro, C., \& Payne, B. K. (2013). The blameworthy victim: Domestic violence myths and the criminalization of victimhood. Journal of Aggression, Maltreatment \& Trauma, 22, 329-347. doi:10.1080/10926771.2013.775985

Reed, E., Raj, A., Miller, E., \& Silverman, J. G. (2010). Losing the "gender" in gender-based violence: The missteps of research on dating and intimate partner violence. Violence Against Women, 16, 348-354. doi:10. 1177/1077801209361127

Saunders, D. G., Lynch, A. B., Grayson, M., \& Linz, D. (1987). The inventory of beliefs about wife beating: The construction and initial validation of a measure of beliefs and attitudes. Violence and Victims, 2, 39-57.

Silván-Ferrero, M., del, P., \& López, A. B. (2007). Benevolent sexism toward men and women: Justification of the traditional system and conventional gender roles in Spain. Sex Roles, 57, 607-614. doi:10.1007/s11199007-9271-8

Ståhl, T., Eek, D., \& Kazemi, A. (2010). Rape victim blaming as system justification: The role of gender and activation of complementary stereotypes. Social Justice Research, 23, 239-258. doi:10.1007/s11211-010-0117-0

Steiger, J. H. (2007). Understanding the limitations of global fit assessment in structural equation modeling. Personality and Individual Differences, 42, 893-898.

Stewart, A., \& Maddren, K. (1997). Police officers' judgements of blame in family violence: The impact of gender and alcohol. Sex Roles, 37, 921-933. doi:10.1007/BF02936347

Taylor, C. A., \& Sorenson, S. B. (2005). Community-based norms about intimate partner violence: Putting attributions of fault and responsibility into context. Sex Roles, 53, 573-589. doi:10.1007/s11199-005-7143-7

Thapar-Björkert, S., \& Morgan, K. J. (2010). "But sometimes I think ... They put themselves in the situation": Exploring blame and responsibility in interpersonal violence. Violence against women, 16, 32-59.

Thornton, B. (1984). Defensive attribution of responsibility: Evidence for an arousal-based motivational bias. Journal of Personality and Social Psychology, 46, 721-734. doi:10.1037/0022-3514.46.4.721

Valor-Segura, I., Exposito, F., \& Moya, M. (2011). Victim blaming and exoneration of the perpetrator in domestic violence: The role of beliefs in a just world and ambivalent sexism. The Spanish Journal of Psychology, 14, 195-206. doi:10.5209/rev_SJOP.2011.v14.n1.17

Vonderhaar, R. L., \& Carmody, D. C. (2015). There are no "innocent victims": The influence of just world beliefs and prior victimization on rape myth acceptance. Journal of Interpersonal Violence, 30, 1615-1632. doi:10.1177/0886260514549196

Waltermaurer, E. (2012). Public justification of intimate partner violence: A review of the literature. Trauma, Violence \& Abuse, 13, 167-175. doi:10.1177/1524838012447699

Wandrei, M. L., \& Rupert, P. A. (2000). Professional psychologists' conceptualizations of intimate partner violence. Psychotherapy: Theory, Research, Practice, Training, 37, 270-283. doi:10.1037/ h0087788

Worden, A. P., \& Carlson, B. E. (2005). Attitudes and beliefs about domestic violence: Results of a public opinion survey: II. Beliefs about causes. Journal of Interpersonal Violence, 20, 1219-1243. doi:10.1177/ 0886260505278531

Yamawaki, N., Ochoa-Shipp, M., Pulsipher, C., Harlos, A., \& Swindler, S. (2012). Perceptions of domestic violence: The effects of domestic violence myths, victim's relationship with her abuser, and the decision to return to her abuser. Journal of Interpersonal Violence, 27, 3195-3212. doi:10.1177/0886260512441253

Yamawaki, N., Ostenson, J., \& Brown, C. R. (2009). The functions of gender role traditionality, ambivalent sexism, injury, and frequency of assault on domestic violence perception: A study between Japanese and American college students. Violence Against Women, 15, 1126-1142. doi:10.1177/1077801209340758

\section{Author Biographies}

Solveig Lelaurain is PhD Student in Social Psychology at Aix-Marseille University. She works on genderbased violence and more specifically, on the psychosocial processes and issues involved in the legitimization of intimate partner violence against women and help-seeking barriers faced by survivors. 
David Fonte, PhD in social psychology, is Temporary Lecturer and Research Assistant at the University of Franche-Comté. His work concerns the normative and identity issues that underlie health behaviours as well as the social representations that legitimize intimate partner violence against women.

Pierluigi Graziani is a full Professor in Clinical Psychology at the University of Nimes, head of the social and humanities department and member of the laboratory of social psychology of Aix-Marseille University. His research activity focuses on addictions, clinical and cognitive psychology and behavioral sciences.

Grégory Lo Monaco is an associate professor (HDR) in social psychology at Aix-Marseille University. He works on social representations theory, social norms and social identity at theoretical, methodological and applied levels. He is member of the executive board and treasurer of the Association for the international dissemination of research in social psychology. 